\title{
Essential public health functions for countries of the Eastern Mediterranean Region: what are they and what benefits do they offer?
}

\author{
Ala Alwan, ${ }^{7}$ Pekka Puska ${ }^{2}$ and Sameen Siddiqi ${ }^{3}$
}

Public health refers to organized efforts to prevent disease, promote health and prolong life among the population as a whole $(1,2)$. Good public health is among the primary responsibilities of ministries of health of all countries, and Member States of the World Health Organization (WHO) Eastern Mediterranean Region are no exception. Equally, helping countries improve their capacity to avert, and when needed respond to, public health challenges is among the primary responsibilities ofWHO. Noble as it is, good public health requires countries to develop their public health system, establish structures and acquire the necessary resources. One way of doing so is by implementing esy sential public health functions (EPHFs). These are an indispensable set of actions, under the primary responsibility of the State, that are fundamental to achieving the goal of public health through collective action (3).

As early as 1994, a landmark publication The essential services of public health addressed the question of EPHFs (4). In the 1990s, WHO also carried out an international Delphi study to define the concept and to confirm which functions are likely to be the most essential (5). In 2002, the Centers for Disease Cons trol and Prevention (CDC), the Latin American Center for Health Research and the Pan American Health Organization proposed a set of 11 EPHFs for the Region of the Americas (3). Country work on EPHFs has also been done by the WHO Regional Office for the
Western Pacific (6), and, more recently, the WHO Regional Office for Europe formulated its "Essential Public Health Operations" relying predominantly on a self-assessment tool (7). Much of the work undertaken by WHO has aimed to serve Member States by helping to assess and develop the EPHFs. The key questions in the assessments are (i) how are the EPHFs carried out in the country, (ii) what agency has the main responsibility and (iii) what is its capacity to perform these?

Strengthening EPHFs is essential for addressing the five areas WHO identified as priorities for the Eastern Mediterranean Region in 2012 (8). For instance, strengthening EPHFs is important for tackling noncommunicable disease prevention and control through multisectoral action and "health in all policies" (9). Similarly, EPHFs can contribute to improving health security as an integral component of national and global security. Good public health requires appropriate administrative structures and resources and calls for the development of specialized expertise. Many countries have responded by strengthening their institutional base with a public health institute (10). Such an institute is often responsible for executing many of the important EPHFs in the country.

The Regional Office for the Eastern Mediterranean has, over the past two years, undertaken the task of establishing EPHFs adapted to the needs of countries of the Region in order to strengthen and improve public health capacity within both Member States and the Regional Office (11). Many Member States of the Region offer public health services, however gaps exist in all countries - rich or poor - that underscore the need for good quality public health work. Health care services, even at their best, deal predominantly with the consequences of diseases. It is well established that these diseases are to a large extent amenable to promotive and preventive interventions and when implemented through organized public health structures are a cost-effective and sustainable way to tackle these health problems.

The work on EPHFs in the Region, which is overseen by a steering committee of public health experts and representatives of international organizations such as the World Bank, United Nations Children's Fund, CDC and International Association of National Public Health Institutes, has identified a set of eight EPHFs adapted to the Region of which four are core and four enabling functions (Box 1). The EPHF initiative has been approached systematically and has progressed from a concept and framework to the development of assessment tools and a guide for assessment. Pilot assessment has been completed in two countries of the Region, Qatar and Morocco. This has involved assessment of the execution of EPHFs and related structures, resources and capacities, first by a national team and then an independent assessment by 


\section{Box 1 Essential public health functions - Eastern Mediterranean Region}

\section{Core functions}

- Surveillance and monitoring of health determinants, risks, morbidity and mortality

- Preparedness and public health response to disease outbreaks, natural disasters and other emergencies

- Health protection including management of environmental, food, toxicological and occupational safety

- Health promotion and disease prevention through population and personal interventions, including action to address the social determinants of health and health inequities

\section{Enabling functions}

- Assuring effective health governance, public health legislation, financing and institutional structures (stewardship function)

- Assuring a sufficient and competent workforce for effective public health delivery

- Supporting communication and social mobilization for health

- Advancing public health research to inform and influence policy and practice

a team of international experts. Generally the experience has been positive and many development needs in the countries have been observed, while at the same time lessons have been learnt to streamline and simplify the assessment process, including the tools. The process is ongoing and currently the experience is being evaluated and the tools modified. Once completed, the next step will be to roll out the initiatives to countries of the Region.

The sole purpose of the work to strengthen EPHFs is to help countries build their capacity to protect and promote the health of their citizens in as cost-effective way as possible, the essence of good public health. Countries can consider different mechanisms to do so. Two that would be fundamental to strengthening EPHFs include strengthening public health governance of the ministries of health and establishing functionally independent national public health institutes. The World Health Organization is committed to helping countries with both.

\section{References}

1. Expert Committee on Public Health Administration: report on the first session. Geneva: World Health Organization; 1952.

2. Acheson D. Public health in England: The Report of the Committee of Inquiry into the Future Development to the Public Health Function. Chmn. Sir D. Acheson (Command Paper). London: Stationery Office Books, 1988 ;

3. Centers for Disease Control and Prevention, Centro Latino Americano de Investigaciones en Sistemas de Salud, Pan American Health Organization/World Health Organization. Public health in the Americas: national level instrument for measuring essential public health functions. Washington DC: Pan American Health Organization; 2000. Pilot test version, May 2000.

4. Harrell JA, Baker EL. The essential services of public health. Leadership Public Health. 1994;3(3): 27-30

5. Bettcher DW, Sapirie S, Goon EH. Essential public health functions: results of the international Dephi study. World Health Stat Q. 1998;51(1):44-54.

6. Essential public health functions A three-country study in the Western Pacific Region. Manilla: World Health Organization Regional Office of the Western Pacific; 2003 (http://www. wpro.who.int/publications/docs/Essential_public_health_ functions.pdf, accessed 1 December 2015)
7. The 10 essential public health operations. Copenhagen: World Health Organization Regional Office for Europe (http://www. euro.who.int/en/what-we-do/health-topics/Health-systems/ public-health-services/policy/the-10-essential-public-healthoperations, accessed 1 December 2015).

8. Shaping the future of health in the WHO Eastern Mediterranean Region: reinforcing the role of WHO. Cairo: World Health Organization Regional Office for the Eastern Mediterranean; 2012 (http://applications.emro.who.int/dsaf/EMROPUB_2012_ EN_742.pdf?ua=1, accessed 1 December 2015).

9. Puska P. Health in All Policies - from what to how. Eur J Public Health. 2014 Feb;24(1):1

10. Koplan JP, Puska P, Jousilahti P, Cahill K, Huttunen J, National Public Health Institute partners. Improving the world's health through national public health institutes. Bull World Health Organ. 2005 Feb;83(2):154-7.

11. Assessment of essential public health functions in countries of the Eastern Mediterranean Region. World Health Organization, Regional Office of the Eastern Mediterranean. http://www. emro.who.int/about-who/public-health-functions/index. html, 1 December 2015). 